\title{
MILLS, C. W. Sobre o artesanato intelectual e outros ensaios. Rio de Janeiro: Jorge Zahar Ed, 2009.
}

\author{
Por Miriam Mabel Sanchez
}

\begin{abstract}
Numa época de adoção de paradigmas fechados de pesquisa, a obra de Mills nos permite visualizar opções de trabalhos nas ciências sociais, comprometidos com "uma aventura intelectual e existencial". Nesta coletânea de textos de Mills (1916-1962), lançada em 2009, mostra-se como a vida acadêmica e o trabalho intelectual se entrelaçam num continuum, no qual o cientista social vai se aperfeiçoando no seu "oficio" de artesão intelectual.
\end{abstract}

A aventura intelectual descrita pelo autor por meio dos textos escolhidos neste livro, denotam uma forte ligação com a vida pessoal e profissional-acadêmica de Mills. A descrição da experiência pessoal no processo de construção, desenvolvimento do conhecimento e a incessante busca de "acalmar a sede intelectual", estão presentes nos relatos biográficos do livro. Sua posição contra a separação entre a vida e o trabalho intelectual, atravessa as várias questões desenvolvidas no decorrer dos trabalhos.

Por outra parte, cabe mencionar que a questão do "artesanato intelectual" se apresentou primeiramente como um ensaio, publicado como apêndice de seu livro "A imaginação sociológica" em 1959. Esta coletânea de textos, contidos no livro tem como eixo organizador , a idéia do "artesanato intelectual".

O livro se encontra organizado por meio de uma breve introdução realizada por Celso Castro, na qual se descreve um pouco a vida de Mills e sua paixão pela "arte da manutenção de motocicletas" (a capa do livro mostra a Mills em sua motocicleta na qual ia para Universidade todos os dias). O primeiro capítulo se estende sobre o tema do "artesanato intelectual", em um relato autobiográfico do autor, que mostra como ele procede em seu "oficio" intelectual, os caminhos escolhidos para chegar a um ponto. Continua com quatro textos breves: o capítulo dois apresenta o tipo ideal do artesanato, algo pouco usual em nossos dias; o capítulo três é uma palestra inédita em português, na qual Mills coloca o artesanato intelectual como um posicionamento fundamental para a vida social; "a promessa" título do capítulo quatro, mostra as possibilidades que a imaginação sociológica pode-nos oferecer e por último, no capítulo cinco, há um texto que vincula o posicionamento do intelectual diante das questões públicas.
Como mencionado, o primeiro capítulo aborda a questão do "artesanato intelectual" como um processo intimamente ligado à vida cotidiana do pesquisador. Esta cotidianidade serve de nutriente para o trabalho intelectual, o que permite um processo de contínua reflexão e interpretação da produção intelectual. Desta forma, em palavras do autor "o conhecimento e uma escolha tanto de um modo de vida quanto de uma carreira, quer o saiba ou não, o trabalhador intelectual forma-se a si próprio, na medida em que trabalha para o aperfeiçoamento de seu oficio, para realizar suas próprias potencialidades (...). Isso significa que deve aprender a usar sua experiência de vida em seu trabalho intelectual: examiná-la e interpretá-la continuamente" (2009, p. 22).

Mills mostra como ele realiza esse processo, por meio de uma linguagem clara, precisa, sem aspirações falsas de academicismo, o próprio percurso de trabalho intelectual. A possibilidade de levar um diário, aonde se vai anotando as reflexões que vão surgindo, as duvidas, as conclusões iniciais, que levam a construção de um arquivo. Tal arquivo consiste em um tipo de combinação "de experiência pessoal e atividades profissionais" no qual se procurara "reunir o que se está fazendo intelectualmente e o que está experimentando como pessoa" (2009, p.22).

Este processo de auto-reflexão, requer de um trabalho do tipo artesanal, que pode implicar na construção de pensamentos mais sistemáticos, ou podem ser subsídios para outras experiências intelectuais. Da mesma forma, esta proposta de trabalho contribui significativamente a desenvolver o hábito de escrever, segundo o autor.

A tomada de notas pode ser um passo inicial para a reflexão sobre alguma questão de relevância, e por isso Mills afirma que "a manutenção de um arquivo assim [é importante para a] produção intelectual. Um repertório sempre crescente de fatos e idéias, desde os mais vagos aos mais acabados" (2009, p.26). O registro possibilita ser um ponto de partida para a concretização de algum projeto, de um livro ou de um artigo. Idéias que parecem ser sem condição, sem relevância podem ser organizadas a partir de um trabalho contínuo que as conecta, as integra em um todo. Dirá Mills, "um bom trabalho em ciência social 
(...) se compõe em base a matérias existentes, teorias que tem a ver com um tópico, materiais já trabalhados por outros como evidências para aquelas teorias; e materiais já reunidos e em diversos estágios de centralização accessível, mas ainda não tornados teoricamente pertinentemente" (2009, p.28-29). Materiais esses, já existentes para desenvolver um tipo de trabalho intelectual que refuta essas teorias ou as aceita, que as utiliza como fontes, e como pontos de partida para as próprias criações intelectuais.

Sobre a pesquisa empírica o autor manifesta que "não há mais virtude na investigação empírica que na leitura" (2009, p.33), apontando claramente que a primeira requer muito trabalho, que é custosa, que precisa de uma equipe, sendo muitas vezes um "exercício formal" para iniciantes na pesquisa, útil "para aqueles que não são capazes de lidar com os problemas substantivos mais difíceis da ciência social (...). O objetivo da investigação empírica é diminuir a discordância e dúvidas acerca dos fatos, e assim tornar discussões mais frutíferas ao basear todos os lados de maneira mais substantiva. Fatos disciplinam a razão; mas a razão évanguarda em qualquer campo do saber"(2009, p. 33, grifo nosso). Os projetos empíricos são "necessários" para o autor, quando estes têm "implicações para construções teóricas", quando são "engenhosos e "bem feitos" e devem prometer uma grande quantidade de dados para a comparação, de modo tal que justifiquem o esforço que significam.

Outra questão abordada neste primeiro capítulo se encontra ligada à idéia de "imaginação sociológica" como passo inicial para o surgimento das idéias. Definida pelo autor, a imaginação sociológica "consiste em parte considerável na capacidade de passar de uma perspectiva para outra e, nesse processo, consolidar uma visão adequada de uma sociedade total e de seus componentes" (2009, p.41). Será este tipo de capacidade a que fará distinção entre o cientista social e o mero técnico, já que a imaginação sociológica supõe combinar idéias e formas não pensadas, não contempladas dessa forma, anteriormente, num esforço por compreender o mundo.

O autor quer deixar clara a distinção entre "tema" e "tópico", a fim de ser uma contribuição na hora de arranjar os materiais para apresentar um trabalho, e dizer tem relação com o "oficio" do trabalhador intelectual. Um tema é uma idéia, uma concepção fundamental, um tópico é um assunto. Um tópico deve conter vários temas, assim como os assuntos devem conter várias idéias. Dessa forma, num trabalho intelectual, as idéias (temas) deveriam estar relacionadas aos tópicos (assuntos) no decorrer de um texto.

Propõe a superação da "prosa acadêmica" por meio da "superação da pose acadêmica" (2009, p.50), com referência ao tipo de linguagem adotada nos textos acadêmicos. Essa posição nos mostra como Mills apesar de sua lucidez intelectual abandona a pose de "intelectual acadêmico ininteligível". Propõe-se que se escreva de forma clara, pode se utilizar termos "técnicos" (que não é o mesmo que difíceis). Expressar de forma clara como se pensa, significa passar da esfera do pensamento para a esfera da apresentação ou "contexto de apresentação", o que implica explorar o contexto da descoberta, já que se terão novas idéias na medida em que se está trabalhando para apresentar suas idéias.

O capítulo dois, intitulado "O ideal do artesanato", mostra como o trabalho intelectual proposto por Mills envolve seis características principais as quais constituem "um modelo como ideal explícito" (2009, p.63):

I. A relação entre o artesão e seu trabalho encontrase mediada pela preocupação pela qualidade do produto que ele fabrica.

II. A própria habilidade, esforço, vencimento de dificuldades se plasmam no produto produzido pelo artesão. Ele tem uma visão "acabada" do produto, o qual Ihe dá uma satisfação particular.

III. Por ser um produto do artesão, ele tem liberdade para começar sua execução, "produção e planejamento" de forma autônoma, ele está no comando, e ele é "responsável por seu resultado e livre para assumir essa responsabilidade" (2009, p.61).

IV. Por meio desse trabalho, o artesão "desenvolve sua habilidade, bem como é um meio para desenvolverse a si mesmo como homem (...). Vive no seu trabalho e através dele, e esse trabalho o manifesta e revela para o mundo" (2009, p.61). O produto de seu trabalho o define e o faz visível ao mundo.

V. Diversão e trabalho não se encontram separados na vida do artesão. Se diversão é fazer algo que nos dá prazer, e se o trabalho nos dá prazer, então trabalho também é diversão. "O artesão (...) trabalha e se diverte no mesmo ato" (2009, p. 62).

VI. A vida que o artesão conhece é a do trabalho, o qual não se encontra separado do lazer. Nos momentos de ócio, sua vida se impregna de "valores e qualidades desenvolvidos e empregados nas horas de trabalho. (...) Assim como leva para seu lazer a capacidade e os problemas de seu trabalho, também traz de volta para o trabalho aquelas sensibilidades que não atingiria em períodos de tensão elevada, constante, necessários para o trabalho consistente" (2009, p.62-63).

No capítulo três, nomeado "O homem no centro: o designer", Mills faz uma aguda interpretação do mundo atual, no qual o designer, o artista, o intelectual exercem seus ofícios. Com esse pano de fundo, aponta que a fim de obter uma compreensão da condição humana, precisamos saber que "os homens vivem em mundos de segunda mão" (2009, p.66). Tal afirmação sustenta- 
se na tese de que entre a consciência e a existência do homem, existe outra instância, outros (...) "padrões e valores que influenciam decisivamente a consciência que possam ter" (2009, p.66). A interpretação que se faz dos fatos concretos, encontra-se mediada, cada vez mais, pelos centros de observação, de interpretação do "aparato cultural". Esse aparato, presente entre os homens e eventos, define significados, valores, percepções que dão certo significado ao mundo. Estes são "organizados, comparados, mantido e revistos, perdidos e encontrados, celebrados e desmascarados" (2009, p.67). Mills define por aparato cultural a "todas aquelas organizações e meios em que o trabalho artístico, intelectual e científico tem lugar. E também a todos os meios pelos quais esse trabalho é tornado acessível a pequenos círculos, públicos mais amplos e grandes massas" (2009, p.67). Nesse contexto, dirá o autor: "as únicas verdades são as verdades definidas pelo aparato cultural" (2009, p.67).

Fazendo referencia aos EUA, o escritor diz que o aparato cultural de tal pais, encontra-se predominantemente estabelecido comercialmente, o que ocasiona a predominância da "cultura comercial", chave para a banalização da cultura. Essa situação afetariaaotrabalhadorintelectual quepermanentemente deve enfrentar a "obsolescência de status", mas por outra parte essa situação seria uma chance para que o designer crie "novas idéias" e as venda da melhor forma possível. Essa busca pela "inovação" contribuiria com o fato do que o "trabalhador cultural tende-se a tornar um escritor comercial" (2009, p.72). Assim, a busca da qualidade do produto estaria colocando num segundo plano o valor do artesanato que é o desenvolvimento humano, é a representação da natureza criativa do trabalho. O trabalho do artesão é um trabalho de ação independente, ele é mestre da atividade e de si mesmo. Em tal processo, se desenvolve como homem e ao mesmo tempo desenvolve sua habilidade, sendo o produto desse tipo de trabalho o que ele mostra para o mundo. E claro que para que artesão possa "florescer", deve existir um público que apóie suas produções, que compreendam o significado desses produtos. Esse tipo de sociedade que vai além do consumo de moda, deveria ser uma sociedade que "está construída em torno do artesanato como experiência central de um ser humano não alienado e [que é] a própria raiz do livre desenvolvimento humano" (2009, p. 80).

A promessa titula o capítulo cinco, traz à reflexão o fato de que o ser humano pareceria não perceber sua conexão com a sociedade. Porém, segundo Mills, as vidas particulares encontram-se ligadas à historia da sociedade na que vivemos, nossas vidas fazem parte da história do mundo e dessa sociedade. Nesta "Idade do Fato", a informação domina e apaga a capacidade de assimilação do homem, adormece sua possibilidade de registrar o mundo circundante. O que os homens precisam para superar esta posição "é uma qualidade mental que os ajude a usar a informação e desenvolver a razão de modo de alcançar sínteses inteligíveis do que está acontecendo dentro deles mesmos (...) essa qualidade pode ser chamada de imaginação sociológica" (2009, p. 83). Resgata-se a idéia de "imaginação sociológica" neste capítulo, mas ligada a um tipo de capacidade que permite ao homem compreender o "cenário histórico mais amplo em termos de sua significação para a vida interior" (2009, p.84).

Biografia e sociedade se entrelaçam por meio da "imaginação sociológica". "Essa é sua tarefa e sua promessa. Reconhecer essa tarefa é a marca do analista social clássico" (2009, p. 84) que Mills propõe como opção de artesão intelectual. Essa visão autoconsciente que o homem tem de si mesmo é a imaginação sociológica, a sua reflexão e sustento para o "significado cultural das ciências sociais".

Por último, a palestra realizada em Rio de Janeiro em 1959, intitulada "O que significa ser um intelectual" é apresentada no capítulo seis. Nele Mills define o que é um intelectual. Dessa forma manifesta que tal os intelectuais percebem constantemente que algo a mais pode ser feito: "Eles contemplam suas pinturas, pensam sobre seus livros, examinam novamente a fórmula e sabem que aquilo não é bom o suficiente e talvez nunca vá ser" (2009, p. 91). Realizam um esforço intelectual, porém Mills adverte que tal tipo de experiência de percepção sensível seja uma experiência alienada.

Outra característica do intelectual seria a condição de desenvolver o "internacionalismo da mente e das sensibilidades" (2009, p.93) como elementos que visam ser sustento para o desenvolvimento do autocultivo consciente e livre uso da mente.

Finalizando, faz referência à relevância do fato de escrever como um meio de produção de trabalho intelectual, o qual denota um processo de reflexão que "corporifica os momentos, horas e dias mais alertas que jamais tivemos" (2009, p. 95).

O livro de Mills convida, por meio de uma linguagem desprovida de poses acadêmicas, à reflexão. A aceitação do convite implica em aceitar o desafio de desfrutar do prazer do trabalho intelectual. A referência autobiográfica permanente no decorrer do livro faz com que o leitor se identifique ou não com o autor na sua tarefa intelectual.

Sendo assim, é uma leitura recomendada útil para aqueles que se iniciam no caminho da vida acadêmica e o trabalho intelectual, e para os mais experientes pode ser sem dúvida alguma, uma fonte para outras inspirações intelectuais. 